\title{
Adherence to a Health Literacy and Healthy Lifestyle with Improved Blood Pressure Control in Iran
}

This article was published in the following Dove Press journal:

Patient Preference and Adherence

\author{
Saber Gaffari-fam (1D) \\ Towhid Babazadeh (iD) ${ }^{2}$ \\ Shahram Oliaei ${ }^{3}$ \\ Leila Behboodi (iD) 4 \\ Amin Daemi $\mathbb{1 D}^{5}$ \\ 'School of Nursing of Miandoab City, \\ Urmia University of Medical Sciences, \\ Urmia, Iran; ${ }^{2}$ Department of Public \\ Health, Sarab Faculty of Medical Sciences, \\ Sarab, Iran; ${ }^{3}$ Center of Submarine and \\ Hyperbaric Medicine, Health Deputy of \\ the Iranian Navy, Tehran, Iran; \\ ${ }^{4}$ Department of Health Education and \\ Promotion, Tabriz University of Medical \\ Sciences, Tabriz, Iran; ${ }^{5}$ Health \\ Management and Economics Research \\ Center, Iran University of Medical \\ Sciences, Tehran, Iran
}

Introduction and Aim: High blood pressure is the leading and most important modifiable risk factor for cardiovascular disease. Health literacy and lifestyle are two paramount key factors behind better control of hypertension. This study was conducted to examine the current situation of health literacy and health-promoting lifestyle and its association with blood pressure control among people affected by hypertension in the population over age 30 of Northwest Iran.

Patients and Methods: This was a cross-sectional study conducted in October and December 2018 on the over 30-year-old population among subjects suffering from hypertension $(n=210)$. A self-reported questionnaire was used for assessing health literacy dimensions and lifestyle.

Results: In hierarchical linear analysis, the HL explained $33.9 \%$ of the variance in healthy lifestyle. Among HL dimensions, the ability to access health information and decisionmaking were significantly associated with healthy lifestyle. The health literacy dimensions contributed to an additional significant increase in $4.7 \%$ of the variance explained in hypertension, furthermore, the health-promoting lifestyle items were explained an additional $14.8 \%$ of the hypertension variance. In total, lifestyle and health literacy dimensions were able to explain $21.7 \%$ of the variance in hypertension.

Conclusion: Our study encourages efforts to monitor health literacy in people with hypertension and investigate associations with involvement with health-promoting lifestyle.

Keywords: health literacy, life style, hypertension
Correspondence: Towhid Babazadeh Department of Public Health, Sarab Faculty of Medical Sciences, Sarab, Iran Tel +984143224586 Fax $+984 \mid 43237412$

Email towhid.babazadeh@gmal.com

\section{Introduction}

Experts forecast that as the world population ages, the incidence of death and disability due to cardiovascular disease (CVD) is likely to increase. ${ }^{1}$ Hypertension is a leading risk factor for mortality globally and is extremely prevalent in many of the largest low- and middle-income countries. ${ }^{2}$

The worldwide prevalence of hypertension in 2000 among adults aged 20 years and older was approximately $26.4 \%$. The prevalence is estimated to be $29.2 \%$ by 2025 which means an increase of $60 \%$, with most of the increase attributed to a rise in economically developing countries and projected changes in the age distribution of the population. ${ }^{3}$

To prevent the hypertension, modifiable risk factors include unhealthy diets (like excessive salt consumption), physical inactivity, consumption of tobacco and alcohol, and being overweight or obese. ${ }^{4}$ In addition, in a study conducted in Yemen, it has been shown that hypertension rates are higher in the coastal area than in the

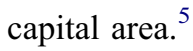


Currently, in spite of effective treatments, only $37 \%$ of patients manage to maintain their blood pressure in levels recommended by health-care practitioners. ${ }^{3}$ Adherence to treatment among patients with hypertension depends on many factors. Several studies have shown that factors such as low socioeconomic status, seriousness of disease, number of pills per day, side effects of medication, patient's insufficient understanding of the disease and co-morbid medical conditions are effective in adherence to treatment. $^{6,7}$

Patients with uncontrolled blood pressure are 50\% more likely to experience a cardiovascular event, like stroke, kidney failure, myocardial infarction, and death, compared to patients with controlled blood pressure. ${ }^{8}$ However, only about half of those with hypertension achieve blood pressure (BP) control, and about 15.9\% remain unaware of their condition. ${ }^{8}$

The latest recommendation suggests diuretics and calcium antagonists (long-acting dihydropyridines) as firststep acute therapy for isolated systolic hypertension. Proof of gain of Angiotensin Converting-Enzyme Inhibitors (ACEIs) does not vary from diuretics, $\beta$-blockers, or calcium channel blockers (CCBs) in their ability to control systolic blood pressure, both in systo-diastolic and in isolated systolic hypertension. ${ }^{9,10}$

Recommendations for improving hypertension-related outcomes have been consistent for decades: maintain a healthy weight, reduce daily sodium intake, increase physical activity, and comply with antihypertensive therapy, as prescribed. ${ }^{10}$ In addition, healthy lifestyle, also, is recommended by the World Health Organization (WHO) to prevent and control high blood pressure. ${ }^{11}$ Lifestyle modifications, such as increasing physical activity and dietary modification, are of confirmed efficiency in lowering hypertension in un-medicated patients with hypertension, ${ }^{12}$ and are often suggested as the first step for controlling high blood pressure. ${ }^{13}$

One of the most important strategies to improve a healthy lifestyle is to increase knowledge and to promote health literacy (HL) among people. ${ }^{12} \mathrm{HL}$ is defined as

The ability to access, understand, evaluate and communicate information as a way to promote, maintain and improve health in a variety of settings across the life-course. ${ }^{13}$

WHO refers to HL as a key element of health and recommends that countries create a multi-stakeholder "Council on Health Literacy", at arm's length from government, to monitor and assess progress, facilitate partnerships between organizations, and provide strategic direction for health literacy. Studies indicated that lower HL is associated with poorer health outcomes and unhealthy behaviors. ${ }^{12,14}$ Also, HL is an effective factor in controlling blood pressure, ${ }^{15-17}$ understanding blood pressure measurements, risk factors and complications, necessary lifestyle changes, and aims of treatment. ${ }^{18,19}$ The findings of a meta-analysis demonstrated that optimal self-care in hypertensive patients could decrease systolic and diastolic blood pressure by 5 and $4.3 \mathrm{mmHg}$, respectively. ${ }^{3}$ It seems that those who are more eager to health-related information take responsibilities and make decisions about their own and their families'. ${ }^{20}$

This study was conducted to examine the current situation of lifestyle and health literacy profiles and its association with blood pressure control among people affected by hypertension in the ages of over 30 population of Northwest Iran. Identifying hypertension influential factors in such studies may be helpful in designing interventional efforts aiming at hypertension control.

\section{Materials and Methods}

\section{Participants and Sampling}

The study was a cross-sectional one which was conducted in October and December 2018 among subjects suffering from hypertension in Tabriz, East Azerbaijan province, Iran. This study was limited to target respondents above the age of 30. In the study, a multistage cluster sampling was employed to recruit 210 people. The sample size calculated based on the Babaei-Sis et al study, ${ }^{21}$ determining sample size was done in $\mathrm{G}^{*}$ Power software with the effect size equal to $0.330, \alpha$ error probability equal to 0.05 , power (1- $\beta$ error probability) equal to 0.95 . The sample size calculated to be approximately 109 . Furthermore, sampling method in this study was cluster sampling, so the design effect must be regarded and the design effect might have been between 1.3 and 2 might. $^{22}$ Finally, we specified the design effect equal to 1.92 . Then the final sample size calculated to be equal to 220. In total, 210 subjects agreed to participate in the study and all people completed the written questionnaire (Response Rate $=95.45 \%$ ). Among the initially thirteen health centers, we randomly selected five centers from which the respondents were randomly selected based on their records in the health centers. Based on the Iranian health system, the health information of all inhabitants is recorded in the health center. Therefore, the respondents 
were randomly selected based on their health records that existed in the health center in order to be invited to participate in the study. The participants signed a written informed consent form when presented in the health center. The respondents, then, completed the questionnaires in a consultation room in the health center. Also, the interview method was applied to gather data from the respondents by the first and second researchers. The interviews lasted 15 mins. The inclusion criteria for this study were limited to patients with hypertension as well as living in suburban areas while the exclusion criterion was only participants' unwillingness to take part in the survey.

\section{Instruments}

In order to collect data, the researchers used three questionnaires; one was a self-administered questionnaire to collect demographic data including age, gender, marital status, job status (employed, unemployed, housewife, retired), education status (illiterate, elementary, intermediate, high school, diploma, associate degree, bachelor).

The second questionnaire was the HL questionnaire, a valid and reliable one that was used to assess HL. ${ }^{23}$ The questionnaire was developed by Montazeri et al for using among Iranian adults. The HL instrument is composed of six domains as follows: 1) Reading health information "constituted of a four-item scale $(\alpha=0.72)$ which was developed to assess health issues pertaining to participants" reading abilities. An example of this domain was: "reading health education materials (booklet, pamphlet, and educational brochures) was easy for me". 2) Understanding health information scale comprised of seven questions $(\alpha=0.86)$ such as "I can acquire the required health and medical information from different sources"; 3) Appraisal of health information was measured by using a four-item scale $(\alpha=0.77)$. For instance, I can get information about healthy nutrition. 4) Ability to access health information was evaluated by a sixitem scale $(\alpha=0.86)$ such as "I can obtain information about my illness"; 5) Decision making was a twelve-item scale $(\alpha=0.89)$ which was developed to measure the ability to decide health-related behaviors. Examples of items were "I avoid doing things or taking materials that might increase my weight" or "I do not stop taking medications without my doctor's permission" even if the symptoms of the disease would be disappeared.

The items for reading health information and the ability to access health information were rated on a five-point Likert-type scale ranging from 1 to 5 (1= completely difficult through $5=$ completely easy). Also, for the appraisal of health information, understanding health information and decision making, the items were rated on a five-point Likerttype scale ranging from 1 to 5 (always $=5$, most of the time $=$ 4 , sometimes $=3$, seldom $=2$ and never $=1$ ). The higher the score, the more HL was concluded.

Finally, we used a valid and reliable instrument to assess lifestyle that developed in 2012 by Lali et al. ${ }^{24}$ The Questionnaire included four dimensions: Psychological health (seven items; $\alpha=0.88$ ), Weight control and nutrition (seven items; $\alpha=0.85$ ), Physical activity (seven items; $\alpha=$ 0.87 ), Avoidance from drugs (six items; $\alpha=0.79$ ). For all four dimensions, the items were rated on a four-point Likerttype scale ranged from 1 to $4(1=$ never through $4=$ always $)$.

\section{Definition of Hypertension}

Hypertension was described as a systolic blood pressure equivalent to or over $140 \mathrm{mmHg}$, or a diastolic blood pressure equivalent to or over $90 \mathrm{mmHg}$, or being under medication for hypertension. Blood pressure measurement was carried out twice on each arm while participants were in sitting position and after 5 mins of seated rest. The two measurements were used with an interval of a few minutes. Accordingly, the average of the second blood pressure measurement on each arm was estimated and recorded (21).

\section{Data Analysis}

We assessed associations of health literacy and healthy lifestyle with blood pressure outcomes using both the measurement-only definitions and medical definitions described above.

The characteristics of participants were summarized as mean ( \pm standard deviation) and frequencies (percentages), for continuous and categorical variables, respectively.

Multivariable models were adjusted for age, sex, education, marital status, family history of diabetes, and, in analyses of the individual lifestyle factors, each of the other lifestyle factors.

All analyses were performed using SPSS 19; two-sided P-values and $95 \%$ CIs are presented.

\section{Results General Characteristics of Study Participants}

A total of 210 individuals agreed to participate in the current study. Table 1 shows the demographic characteristics of the participants and their associations with 
Table I Demographic Characteristics of the Study Participant and Their Association with Life Style and Health Literacy

\begin{tabular}{|c|c|c|c|c|c|c|}
\hline \multicolumn{2}{|l|}{ Variable } & \multirow[t]{2}{*}{ Frequency (Percent) } & \multirow{2}{*}{$\begin{array}{l}\text { Life Style } \\
\text { Mean ( } \pm \text { SD) }\end{array}$} & \multirow[t]{2}{*}{ P-value } & \multirow{2}{*}{$\begin{array}{l}\text { Health Literacy } \\
\text { Mean ( } \pm \text { SD) }\end{array}$} & \multirow[t]{2}{*}{ P-value } \\
\hline & & & & & & \\
\hline Age & $\begin{array}{l}\leq 40 \\
41 \text { to } 50 \\
50 \leq\end{array}$ & $\begin{array}{l}66(31.4) \\
65(31.0) \\
79(37.6)\end{array}$ & $\begin{array}{l}76.45( \pm 14.08) \\
78.72( \pm 11.62) \\
76.50( \pm 11.16)\end{array}$ & 0.764 & $\begin{array}{l}83.59( \pm 22.35) \\
84.09( \pm 27.12) \\
76.32( \pm 28.53)\end{array}$ & 0.136 \\
\hline Gender & $\begin{array}{l}\text { Male } \\
\text { Female }\end{array}$ & $\begin{array}{l}97(46.2) \\
113(53.8)\end{array}$ & $\begin{array}{l}79.03( \pm 11.19) \\
75.58( \pm 12.97)\end{array}$ & 0.042 & $\begin{array}{l}87.34( \pm 23.30) \\
75.58( \pm 27.79)\end{array}$ & 0.001 \\
\hline Education Level & $\begin{array}{l}\text { Illiterate } \\
\text { High-school } \\
\text { Diploma and higher }\end{array}$ & $\begin{array}{l}98(46.7) \\
40(19.0) \\
72(34.3)\end{array}$ & $\begin{array}{l}74.61( \pm 13.66) \\
78.05( \pm 10.31) \\
80.18( \pm 10.55)\end{array}$ & 0.012 & $\begin{array}{l}66.83( \pm 24.59) \\
80.60( \pm 24.55) \\
100.54( \pm 15.25)\end{array}$ & 0.001 \\
\hline Marital Status & $\begin{array}{l}\text { Married } \\
\text { Single }\end{array}$ & $\begin{array}{l}199(94.8) \\
11(5.2)\end{array}$ & $\begin{array}{l}77.36( \pm 12.37) \\
73.77( \pm 10.28)\end{array}$ & 0.340 & $\begin{array}{l}81.38( \pm 26.70) \\
74.27( \pm 20.44)\end{array}$ & 0.386 \\
\hline Job Status & $\begin{array}{l}\text { Employee } \\
\text { Self-employed } \\
\text { Housekeeper } \\
\text { Retired }\end{array}$ & $\begin{array}{l}48(22.9) \\
16(7.6) \\
101(48.1) \\
45(21.4)\end{array}$ & $\begin{array}{l}79.68( \pm 10.26) \\
81.06( \pm 12.86) \\
74.81( \pm 13.17) \\
78.42( \pm 11.20)\end{array}$ & 0.047 & $\begin{array}{l}88.56( \pm 19.60) \\
90.50( \pm 20.69) \\
71.95( \pm 27.30) \\
89.93( \pm 26.45)\end{array}$ & 0.001 \\
\hline
\end{tabular}

lifestyle and health literacy. Of the participants $53.8 \%$ were female and the mean age was $56.70( \pm 1.11)$ years. The table demonstrates that the scores of lifestyle and health literacy were lower among women. The strong evidence also suggests that those with a higher level of education had higher scores of health literacy and lifestyle.

Men had lower systolic $[146.6( \pm 18.4)$ vs. 146.7 $( \pm 19.0) \mathrm{mmHg}(\mathrm{P}$-value $=0.977)]$ and diastolic [88.9 $( \pm 15.1)$ vs. $91.1( \pm 12.4) \mathrm{mmHg}(\mathrm{P}-$ value $=0.250)]$ blood pressure than women.

\section{Factors of Health Literacy and the Blood Pressure}

To assess the predictive validity of the health literacy dimensions over lifestyle, hierarchical regression was employed. The results revealed that, in step 1, age, gender, level of education, marital status and job status were collectively able to explain $6 \%$ of the variance in lifestyle score $(p$-value $=0.027)$. Inclusion of reading health information, ability to access health information, understanding health information, appraisal of health information and decision-making at step 2 contributed a further significant increase in $33.9 \%$ of the variance explained in lifestyle (p-value $<0.001$ ) [Table 2]. Moreover, the level of education was a significant predictor of lifestyle in the first models while was not significant in the second model.

In Table 3, hierarchical regression was applied to evaluate the predictive validity of health literacy and health it's over hypertension. The results revealed that, in step 1, age, gender, level of education, marriage and job were collectively able to explain $2.2 \%$ of the variance in hypertension

Table 2 Hierarchical Linear Regression of Life Style Onto Demographic Characteristics and Health Literacy

\begin{tabular}{|l|l|l|l|l|}
\hline Variables & B & $\begin{array}{l}\text { R2 } \\
\text { Change }\end{array}$ & F Change & SE \\
\hline Step I & Age & & & \\
Gender & 0.054 & 0.060 & 2.59 & 1.31 \\
Education level & $0.197^{*}$ & & & 1.87 \\
Marriage & -0.609 & & & 0.99 \\
Job & -0.091 & & & 3.37 \\
\hline Step 2 & & & & 0.88 \\
Age & 0.032 & $0.339 * *$ & 22.45 & 0.932 \\
Gender & 0.005 & & & 1.54 \\
Education level & 0.077 & & & 1.020 \\
Marriage & 0.042 & & & 0.732 \\
Job & 0.02 & & & 3.11 \\
Reading health & 0.022 & & & 0.21 \\
information & & & & \\
Ability to access & $0.179 *$ & & & 0.164 \\
health information & & & & \\
Understanding health & 0.080 & & & 0.145 \\
information & & & & \\
Appraisal of health & 0.051 & & & \\
information & & & & \\
Decision-making & $0.476 * *$ & & & \\
\hline
\end{tabular}

Notes: $\mathrm{R} 2=0.399 ;{ }^{*} \mathrm{p}<0.05 ;{ }^{* *} \mathrm{p}<0.01$. 
Table 3 Hierarchical Linear Regression of Systolic Hypertension Onto Demographic Characteristics, Health Literacy and Life Style

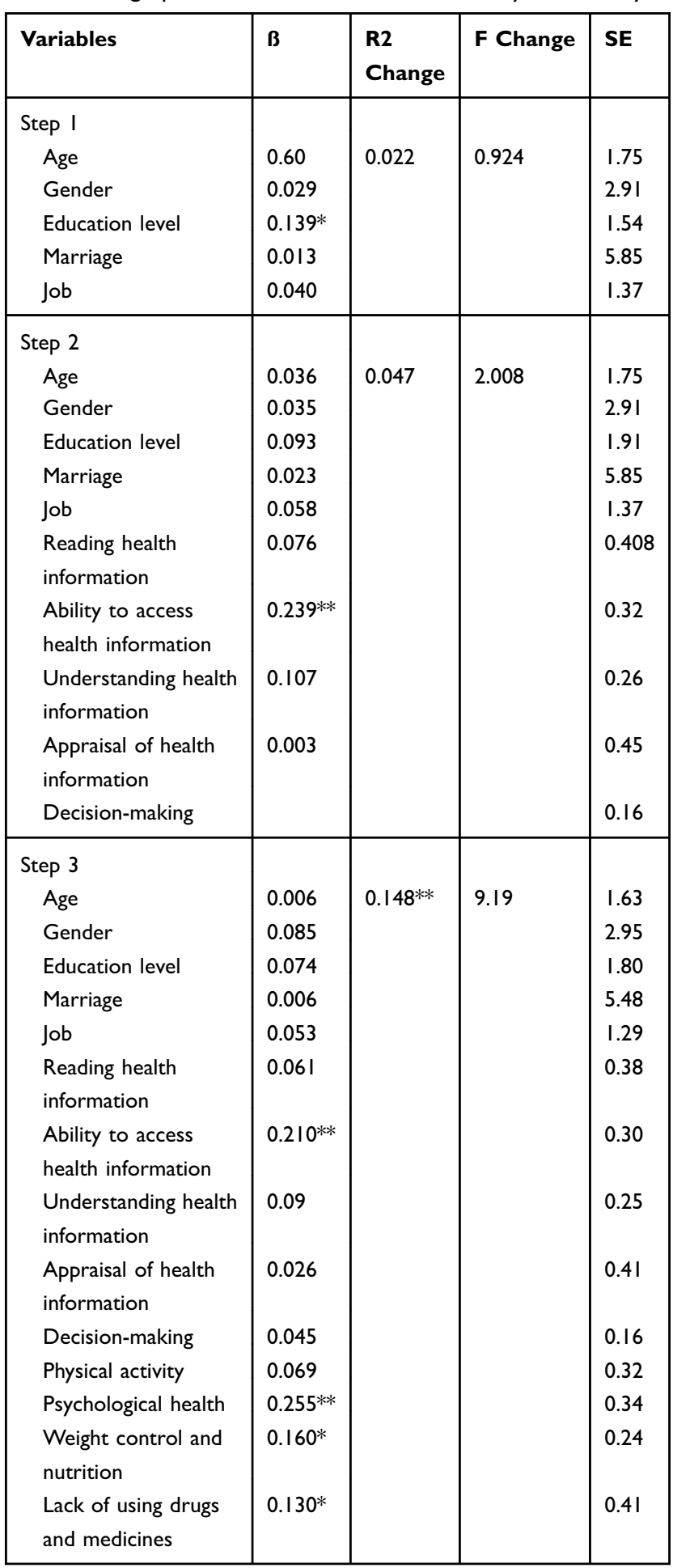

Notes: $\mathrm{R} 2=0.217 ;{ }^{*} \mathrm{p}<0.05 ;{ }^{*} \mathrm{p}<0.01$.

$(p$-value $=0.467)$. Inclusion of reading health information, ability to access health information, understanding health information, appraisal of health information and decisionmaking at step 2 contributed a further significant increase in $4.7 \%$ of the variance explained in hypertension $(p$-value $=0.079)$ [Table 3]. In final step, lifestyle dimensions were added, which explained an additional $14.8 \%$ of the variance ( $\mathrm{p}$-value $<0.001$ ) [Table 3]. In total, lifestyle and health literacy dimensions were able to explain $21.7 \%$ of the variance in hypertension [Table 3].

\section{Discussion}

Blood pressure control in hypertensive patients was regarded as an established challenge. This can be more challenging when hypertensive patients have limited health literacy. The results of this study reinforce the importance of adhering to healthy lifestyle habits and health literacy for hypertension patients.

Our findings indicated significant differences in health literacy by the patient's level of education, gender, and occupation. The current study reported that education level is associated with possessing a higher level of health literacy and a healthy lifestyle. In the hierarchical regression analysis, the level of education was the only significant predictor of lifestyle in the first step of the analysis. Previous studies reported similar findings. ${ }^{25-27}$ In addition, Sun et al, reported that education has a positive and direct effect on prior knowledge and health literacy. ${ }^{28}$ This should help the policy of focusing on promoting health literacy and integrating the education of knowledge of specific diseases in the school curriculum. Since childhood, this information related to health should be given extensively to avoid lifestyle-related disease.

Our results showed that of the HL dimensions, the ability to access health information and decision-making were significant predictors of lifestyle and explained approximately $34 \%$ of the variance in the model. Our findings are comparable to previous studies of Health literacy in Malaysia, ${ }^{26}$ China, $^{29}$ and Japan, ${ }^{30}$ which emphasized the importance of health literacy towards healthy lifestyle habits. Dominick et al found that the higher the health literacy, the higher physical activity selfefficacy. ${ }^{31}$ Sajjadi et al reported a correlation between health literacy and stress control so that those women with higher literacy had lower stress control. ${ }^{32}$ Other studies showed that limited health literacy is related to fewer healthy lifestyle behaviors, ${ }^{33}$ and more risky behaviors. ${ }^{34}$ These findings are beneficial since health literacy is a modifiable determinant of health. Therefore, it is recommended that health planners when educational interventions to improve lifestyle should be focus on promoting health literacy. 
Based on our findings, HL dimensions contributed a further significant increase in $4.7 \%$ of the variance explained in hypertension. In other words, HL dimensions only predict $4.7 \%$ of the variations in blood pressure.

$\mathrm{HL}$ is the capacity of an individual to get, interpret, and understand information that is necessary for decisions about health and health services. For example, older people with a lower level of health literacy may have problems in understanding the instructions of blood pressure control medicines. ${ }^{29}$ Lor et al in a study among Hispanic adults in the US demonstrated that when controlling for individually significant covariates, $13.6 \%$ of the variation in medication adherence is explained by health literacy level. ${ }^{35}$ Patients with low health literacy who are able to access the health-care system and have a diagnosis of hypertension or prescribed treatment have no disparities in blood pressure control. ${ }^{36}$ Literacy may reflect the ability to seek out and access primary care healthcare, obtain follow-up for those conditions and/or comprehend written directions for medications and health information provided which are all essential steps in the management of one's health. ${ }^{37}$ Schumacher et al found that patients with low health literacy had fewer doctor office visits, greater emergency department use, and had more potentially preventable hospital admissions than those with adequate health literacy. ${ }^{38}$ Powers et al showed significant differences in the relationship between patients' literacy and improvement in systolic blood pressure among various models of health services, as well as the effectiveness of features of health service systems on the relationship between literacy and improved health. ${ }^{39}$ Despite the reach evidence regarding the importance of poor literacy and inadequate health literacy, many doctors and educators either lack awareness or necessary skills and self-confidence to approach the subject, ${ }^{40}$ while according to previous studies, the main sources of acquiring health information included doctors (38.5\%), medical personnel (33.7\%), and proper use of medication $94.9 \% .{ }^{41}$ The Chajaee et al mentioned the mean value of health literacy was adequate for accessing and understanding and behavioral intention categories, and the lowest mean value was observed in the reading and appraisal categories, ${ }^{42}$ this finding is coherent with this study.

In total, lifestyle and health literacy dimensions were able to explain $21.7 \%$ of the variance in hypertension. Some studies have reported that patients with hypertension did not have statistically significant differences between health literacy and blood pressure control. ${ }^{43,44}$

\section{Limitation}

Patients presenting with extremely elevated readings may also be more likely to have medication administered and have additional blood pressure measurements recorded. One of the main limitations of this study is the crosssectional design of the study which restricts examining causal associations.

\section{Conclusion}

Our study displayed a positive association between HL and healthy lifestyle practice. A lack of information and understanding of certain diseases and deprived skills in health literacy can explain unhealthy lifestyle behavior. These results highlight the importance of thorough evaluations, including HL, for community health promotion and the need to develop HL to reduce hypertension through a healthy lifestyle. Our findings may guide future work to address the potential relationships between health literacy and hypertension awareness, diagnosis, and control among this vulnerable population.

\section{Ethical Approval}

All procedures performed in studies involving human participants were in accordance with the ethical standards of the institutional and/or national research committee and with the 1964 Helsinki declaration and its later amendments or comparable ethical standards. Ethical approval to perform the study was obtained from the Ethics Committee in Sarab Faculty of Medical Sciences.

\section{Informed Consent}

Informed consent was obtained from all individual participants included in the study.

\section{Acknowledgment}

The authors would like to thank all personnel of Health vice-chancellery of Tabriz University of Medical Sciences for their cooperation.

\section{Disclosure}

The authors declare that they have no conflicts of interest regarding this study.

\section{References}

1. Yusuf S, Reddy S, Ônpuu S, Anand S. Global burden of cardiovascular diseases: part I: general considerations, the epidemiologic transition, risk factors, and impact of urbanization. Circulation. 2001;104 (22):2746-2753. doi:10.1161/hc4601.099487 
2. Misra P, Kant S, Salve H, Anand K, Srivastava R. Prevalence of adherence to treatment of hypertension and its determinants in Rural Haryana, North India. Int J Epidemiol. 2015;44:123-124. doi:10.10 93/ije/dyv096.108

3. Ettehad D, Emdin CA, Kiran A, et al. Blood pressure lowering for prevention of cardiovascular disease and death: a systematic review and meta-analysis. Lancet. 2016;387(10022):957-967. doi:10.1016/ S0140-6736(15)01225-8

4. Worl Health Organization. Hypertension: fact sheet. Available from: https://www.who.int/news-room/fact-sheets/detail/hypertension. Accessed February 2, 2020.

5. Modesti PA, Bamoshmoosh M, Rapi S, Massetti L, Al-hidabi D, Al Goshae H. Epidemiology of hypertension in Yemen: effects of urbanization and geographical area. Hypertens Res. 2013;36(8):711-717. doi:10.1038/hr.2013.14

6. Osterberg L, Blaschke T. Review articles-drug therapy: adherence to medication. $N$ Engl J Med. 2005;353(5):487-497. doi:10.1056/ NEJMra050100

7. Wang PS, Bohn RL, Knight E, Glynn RJ, Mogun H, Avorn J. Noncompliance with antihypertensive medications. J Gen Intern Med. 2002;17(7):504-511. doi:10.1046/j.1525-1497.2002.00406.x

8. Benjamin EJ, Virani SS, Callaway CW, et al. American Heart Association Council on epidemiology and prevention statistics committee and stroke statistics subcommittee. Heart disease and stroke statistics-2018 update: a report from the American Heart Association. Circulation. 2018;137(12):e67-e492.

9. Hansson L, Lindholm LH, Ekbom T, et al. Randomised trial of old and new antihypertensive drugs in elderly patients: cardiovascular mortality and morbidity the Swedish trial in old patients with hypertension-2 study. Lancet. 1999;354(9192):1751-1756. doi:10.10 16/S0140-6736(99)10327-1

10. Whelton PK, He J, Appel LJ, et al. Primary prevention of hypertension: clinical and public health advisory from the national high blood pressure education program. JAMA. 2002;288(15):1882-1888. doi:10.1001/jama.288.15.1882

11. Gharipour M, Sarrafzadegan N, Sadeghi M, et al. The metabolic syndrome and associated lifestyle factors among the Iranian population. Adv Biomed Res. 2015;4.

12. Golshahi J, Ahmadzadeh H, Sadeghi M, Mohammadifard N, Pourmoghaddas A. Effect of self-care education on lifestyle modification, medication adherence and blood pressure in hypertensive adults: randomized controlled clinical trial. Adv Biomed Res. 2015;4.

13. Hasandokht T, Farajzadegan Z, Siadat ZD, Paknahad Z, Rajati F. Lifestyle interventions for hypertension treatment among Iranian women in primary health-care settings: results of a randomized controlled trial. J Res Med Sci. 2015;20(1):54.

14. Harpham T. Urbanization and mental health in developing countries: a research role for social scientists, public health professionals and social psychiatrists. Soc Sci Med. 1994;39(2):233-245. doi:10.1016/ 0277-9536(94)90332-8

15. Abedi P, Soo LMH, Kandiah M, Yassin Z, Shojaezadeh D, Hosseini M. Lifestyle change using the health belief model to improve cardiovascular risk factors among postmenopausal women. Health System Research. 2011;7(1):127-137.

16. Bonaccorsi G, Modesti PA. Health literacy, a new perspective for patient empowerment in the public health approach to hypertension. Intern Emerg Med. 2017;12(6):737-739. doi:10.1007/s11739-017-1657-1

17. Halladay JR, Donahue KE, Cené CW, et al. The association of health literacy and blood pressure reduction in a cohort of patients with hypertension: the heart healthy lenoir trial. Patient Educ Couns. 2017;100(3):542-549. doi:10.1016/j.pec.2016.10.015

18. Bozorgmanesh M, Hadaegh F, Mehrabi Y, Azizi F. A point-score system superior to blood pressure measures alone for predicting incident hypertension: Tehran Lipid and Glucose Study. J Hypertens. 2011;29(8):1486-1493. doi:10.1097/HJH.0b013e3283 $48 \mathrm{fdb} 2$
19. Babazadeh T, Dianatinasab M, Daemi A, Nikbakht HA, Moradi F, Ghaffari-fam S. Association of self-care behaviors and quality of life among patients with type 2 diabetes mellitus: Chaldoran County, Iran. Diabetes Metab J. 2017;41(6):449-456. doi:10.4093/dmj.2017.41.6.449

20. Fahed AC, El-Hage-Sleiman A-KM, Farhat TI, Nemer GM. Diet, genetics, and disease: a focus on the Middle East and North Africa region. J Nutr Metab. 2012;2012.

21. Babaei-Sis MRS, Mahmoodi H, Babazadeh T, Moradi F, Mirzaeian K. The effect of educational intervention of life style modification on blood pressure control in patients with hypertension. J Educ Community Health. 2016;3(1):12-19. doi:10.21859/jech-03012

22. Haghdoost A. Do you want to gain a profound insight into sample size and statistical power. Iran j Epidemiol. 2009;5(1):57-63.

23. Montazeri A, Tavousi M, Rakhshani F, et al. Health Literacy for Iranian Adults (HELIA): development and psychometric properties. Payesh. 2014;13(5):589-599.

24. Lali MAA, Kajbaf MB. Construction and validation of the Lifestyle Questionnaire (LSQ). Psychol Res. 2012;15(1):64-80.

25. Wu Y, Wang L, Cai Z, Bao L, Ai P, Ai Z. Prevalence and risk factors of low health literacy: a community-based study in Shanghai, China. Int J Environ Res Public Health. 2017;14(6):628. doi:10.3390/ ijerph14060628

26. Froze S, Arif M. Determinants of health literacy and healthy lifestyle against metabolic syndrome among major ethnic groups of Sarawak, Malaysia: a multi-group path analysis. Open Public Health J. 2019;12:1. doi:10.2174/1874944501912010172

27. Babazadeh T, Nadrian H, Ranjbaran S, Rezakhani-Moghaddam H, Aghemiri M. Cognitive factors associated with brucellosis preventive behaviours among diagnosed patients: an application of empowerment model. East Mediterr Health J. 2019;25(8):567-574. doi:10. 26719/emhj.18.062

28. Sun X, Shi Y, Zeng Q, et al. Determinants of health literacy and health behavior regarding infectious respiratory diseases: a pathway model. BMC Public Health. 2013;13(1):261. doi:10.1186/1471-2458-13-261

29. Yang S-C, Luo Y-F, Chiang C-H. The associations among individual factors, eHealth literacy, and health-promoting lifestyles among college students. J Med Internet Res. 2017;19(1):e15. doi:10.2196/ jmir.5964

30. Kudo N, Yokokawa H, Fukuda H, Hisaoka T, Isonuma H, Naito T. Analysis of associations between health literacy and healthy lifestyle characteristics among Japanese outpatients with lifestyle-related disorders. J Gen Fam Med. 2016;17(4):299-306. doi:10.14442/jgfm.17.4_299

31. Dominick GM, Dunsiger SI, Pekmezi DW, Marcus BH. Health literacy predicts change in physical activity self-efficacy among sedentary latinas. J Immigr Minor Health. 2013;15(3):533-539. doi:10.1007/s10903-012-9666-7

32. Sajjadi H, Hosseinpour N, Sharifian Sani M, Mahmoodi Z. Association between health literacy and life style in married rural women in Izeh, Iran. J Health. 2016;7(4):479-489.

33. Von Wagner C, Knight K, Steptoe A, Wardle J. Functional health literacy and health-promoting behaviour in a national sample of British adults. J Epidemiol Public Health Rev. 2007;61(12):10 86-1090. doi:10.1136/jech.2006.053967

34. Adams RJ, Piantadosi C, Ettridge K, et al. Functional health literacy mediates the relationship between socio-economic status, perceptions and lifestyle behaviors related to cancer risk in an Australian population. Patient Educ Couns. 2013;91(2):206-212. doi:10.1016/ j.pec.2012.12.001

35. Lor M, Koleck TA, Bakken S, Yoon S, Navarra A-MD. Association between health literacy and medication adherence among hispanics with hypertension. J Racial Ethn Health Disparities. 2019;6 (3):517-524. doi:10.1007/s40615-018-00550-z

36. McNaughton CD, Kripalani S, Cawthon C, Mion LC, Wallston KA, Roumie CL. Association of health literacy with elevated blood pressure: a cohort study of hospitalized patients. Med Care. 2014;52 (4):346. doi:10.1097/MLR.0000000000000101 
37. Baker DW, Gazmararian JA, Williams MV, et al. Health literacy and use of outpatient physician services by medicare managed care enrollees. J Gen Intern Med. 2004;19(3):215-220. doi:10.1111/ j.1525-1497.2004.21130.x

38. Schumacher JR, Hall AG, Davis TC, et al. Potentially preventable use of emergency services: the role of low health literacy. Med Care. 2013;51(8):654. doi:10.1097/MLR.0b013e3182992c5a

39. Powers BJ, Olsen MK, Oddone EZ, Thorpe CT, Bosworth HB. Literacy and blood pressure-do healthcare systems influence this relationship? A cross-sectional study. BMC Health Serv Res. 2008;8 (1):219. doi:10.1186/1472-6963-8-219

40. Tol A, Pourreza A, Foroshani R, Tavassoli E. Assessing the effect of educational program based on small group on promoting knowledge and health literacy among women with type 2 diabetes referring to selected hospitals affiliated to Tehran University of Medical Sciences. Razi J Med Sci. 2013;19(104):10-19.
41. Barzkar H, Nikbakht H-A, Zeinolabedini M, Babazadeh T, Hassanipour S, Ghaffari-fam S. Factors associated with therapeutic target achievement in the control of complications in consequence of diabetes: a hospital-based study in west of Iran. Diabetes Metab Syndr. 2019;13(3):2009-2013. doi:10.1016/j.dsx.2019.04.031

42. Chajaee F, Pirzadeh A, Hasanzadeh A, Mostafavi F. Relationship between health literacy and knowledge among patients with hypertension in Isfahan province, Iran. Electron Physician. 2018;10 (3):6470. doi:10.19082/6470

43. Williams MV, Baker DW, Parker RM, Nurss JR. Relationship of functional health literacy to patients' knowledge of their chronic disease: a study of patients with hypertension and diabetes. Arch Intern Med. 1998;158(2):166-172. doi:10.1001/archinte.158.2.166

44. Battersby C, Hartley K, Fletcher A, et al. Cognitive function in hypertension: a community based study. J Hum Hypertens. 1993;7(2):117-123.

\section{Publish your work in this journal}

Patient Preference and Adherence is an international, peer-reviewed, open access journal that focuses on the growing importance of patient preference and adherence throughout the therapeutic continuum. Patient satisfaction, acceptability, quality of life, compliance, persistence and their role in developing new therapeutic modalities and compounds to optimize clinical outcomes for existing disease states are major areas of interest for the journal. This journal has been accepted for indexing on PubMed Central. The manuscript management system is completely online and includes a very quick and fair peer-review system, which is all easy to use. Visit http:// www.dovepress.com/testimonials.php to read real quotes from published authors. 